\title{
La formación de los conservadores-restauradores en Chile: contexto, balance y desafíos
}

\author{
Magdalena Krebs Kaulen
}

Resumen: Se destacan algunos hitos que dan cuenta de cómo se ha instalado la preocupación por el patrimonio cultural en Chile entre los especialistas, en la población en general y en el ámbito de las políticas públicas. Se explica la situación actual de la institucionalidad que tiene por misión cautelar el patrimonio de la nación y se da narra el desarrollo que ha tenido la formación de conservadores y restauradores en el país. Finalmente se trazan los desafíos que se presentan en el ámbito de la formación de la disciplina de la conservación/restauración.

Palabras clave: Formación, conservación/restauración, patrimonio cultural, institucionalidad

\begin{abstract}
In this study we point out several landmarks that show how the concern for Chilean cultural heritage has risen among professionals, the population in general and public policy. We will explain the actual situation of the institutions that must care for the nation's heritage and what the formation and training of restorers and conservators has been like in this country. Finally, we will talk about the new challenges that have appeared in the area of the training of Conservation and Restoration.
\end{abstract}

Keywords: Training, Conservation, Restoration, Cultural Heritage, Public Institutions

Resumo: Destacam-se algums marcos históricos que nos dão a entender como foi instalada a preocupação pelo Património Cultural em Chile entre os especialistas, na população em geral e no âmbito das políticas públicas. Explica-se a situação actual da institucionalidade que têm por missão cautelar o património da nação, descrevendo-se o desenvolvimento que teve a formação de conservadores e restauradores no país. Finalmente traçam-se os desafios que se apresentam no âmbito da formação da disciplina da conservação/restauração.

Palavras-chave: Formação, conservação/restauração, Património Cultural, institucionalidade.

\section{Día del Patrimonio Cultural}

Desde hace ya diez años que el último domingo del mes de mayo se celebra en Chile el Día del Patrimonio Cultural. Esta celebración instituida por el Consejo de Monumentos Nacionales, [www.monumentos.cl] la entidad cuyo fin primordial es normar las acciones sobre el patrimonio inmueble de Chile y la Dirección de Bibliotecas, Archivos y Museos [www.dibam.cl], que como su nombre lo señala tiene como principal fin el patrimonio mueble y que administra los museos, bibliotecas y archivos estatales, coordina el sistema de bibliotecas públicas y presta diversos servicios especializados, tales como la conservación a través del Centro Nacional de Conservación y Restauración.

Este día se ha constituido en una verdadera fiesta nacional, que sin celebrar ningún acontecimiento específico festeja, con gran apoyo de los medios de comunicación, la gesta colectiva de construcción del país. Un enorme grupo de voluntarios, principalmente estudiantes, pero también las máximas autoridades, como la presidenta del país, los intendentes y alcaldes, actúan como dedicados y cordiales anfitriones y reciben a familias completas que ordenada y alegremente visitan 
edificios históricos e instituciones emblemáticas, junto con espacios públicos engalanados y crecientemente también sitios naturales a lo largo de todo el país.

Una iniciativa de bajo costo, con una visibilidad enorme ha logrado que este día se constituya en la mejor campaña imaginable para promover el conocimiento del patrimonio cultural y promover su apropiación permanente de parte de la población. Su instauración ha situado en la agenda pública al patrimonio cultural y ha permitido llamar la atención del mundo político sobre el anhelo de la población para la conservación de su memoria y de sus formas de vida. Este objetivo es significativo y creo se ha cumplido plenamente. Tal vez con el tiempo se pueden agregar otras acciones como llamar la atención para un uso sustentable, o bien iniciar y/o dar a conocer la importancia de desarrollar programas de mantenimiento y conservación de largo plazo.

\section{Programa Puesta en Valor del Patrimonio}

Otra iniciativa que merece ser destacada es el Programa Puesta en Valor del Patrimonio, proyecto de conservación del patrimonio inmueble en diversas regiones del país, gestionado por la Subsecretaría de Desarrollo Regional y Administrativo (SUBDERE) en conjunto con el Ministerio de Obras públicas (MOP), y para el cual se ha conseguido un crédito del Banco Interamericano de Desarrollo (BID). El fin es "recuperar los Monumentos Nacionales distribuidos a lo largo de las quince regiones, priorizar la mejora de los inmuebles de relevancia territorial e invertir en los patrimonios de nuestro país, con el fin de incorporar más activos al proceso de desarrollo económico y social de los territorios". Se busca que el programa contribuya a "la protección y restauración de bienes culturales, incluyendo edificios, áreas urbanas y lugares de interés artístico o histórico". Los gestores esperan que "con la participación de los gobiernos regionales, el programa incorpore la protección y restauración cultural como parte del proceso de desarrollo." 1

Este programa nace de las más altas esferas del gobierno y reúne dos ministerios, busca que el patrimonio se inserte en un sistema que se vincule con las redes que se encuentran a su alrededor. Esto es lo que Verónica Serrano, directora de arquitectura del MOP y máxima responsable de este programa destaca, cuando señala que "el patrimonio no es intocable: debe convivir con la comunidad" y luego explica que "queremos generar una valorización del patrimonio en la comunidad, pero también generar más expertise dentro de los especialistas sobre cómo abordar el tema, y no necesariamente trabajarlas desde el punto de vista de la restauración, sino de la gestión del patrimonio, con una visión más abierta" (Serrano, 2007) aseveración que insinúa una tensión entre restauración y gestión, como si estos no fuesen compatibles y complementarios sino antagónicos. Creo reconocer en esta afirmación una preocupación que estimo real en cuanto a que se ha tendido a sacralizar el patrimonio, muchas veces limitando su uso o bien musealizándolo, dejándolo para la contemplación. Sin embargo este enfoque encierra un riesgo para la disciplina y el bien hacer, pues si se cambia el eje y las decisiones se entregan solamente a gestores y/o a la comunidad, sin el debido apoyo profesional, se corre el riesgo que las intervenciones no recojan las buenas prácticas generadas por la profesión en décadas de experiencia.

El programa es de gran ambición y de una magnitud no vista en el país con anterioridad. Busca que simultáneamente en todas las regiones (por algo se sitúa desde la SUBDERE, que tiene como objetivo contribuir al desarrollo de los territorios, fortaleciendo su capacidad de buen gobierno), se postulen en base a proyectos a este fondo para la recuperación del patrimonio, poniendo como exigencia un plan de gestión asociado. El programa ha generado controversia, pues se contrajo este compromiso antes de tener un plan acabado en términos técnicos o administrativos para su implementación. Al respecto el conocido arquitecto e historiador y especialista en patrimonio Hernán Rodríguez expone sus dudas, dando cuenta de una cierta improvisación en el programa; se pregunta si existe un listado de edificios para esta inversión, consulta si habrá uno o más comités de evaluación, si participará el Consejo de Monumentos en la selección, si los dineros se administrarán 
como fondo concursable, si el programa responderá a criterios técnicos, a planes de gestión, a puntajes ponderados, a porcentajes fijos o variables por región (Rodríguez 2008).

Como en tantas otras iniciativas existe una fuerte tensión entre las buenas intenciones del nivel central de la administración estatal y las posibilidades e intereses de las regiones para ejecutarlo. Junto a los problemas de implementación y a las conflictos administrativos, las principales dificultades que ha debido abordar el programa, se refieren a la falta de capacidades instaladas en las entidades regionales para la formulación de proyectos y asimismo para la formulación de bases de referencia para llamar a licitación y por otro lado al insuficiente número de equipos de especialistas en el sector privado, preparados para asumir las exigencias de los requerimientos en los plazos exigidos. Nos encontramos en un punto intermedio, antes no había especialistas, pues no había demanda, ahora se ha generado esta demanda y no tenemos suficientes especialistas. En ese sentido este programa ha sido positivo, pues ha abierto un verdadero mercado de trabajo, antes inexistente en este ámbito en Chile, y será interesante observar si ello consolida la existencia de al menos algunas oficinas y empresas especializadas en restauración.

\section{Patrimonio de la Humanidad, planes de manejo y normativas}

Tras la declaración para Isla de Pascua en el año 1995 como Patrimonio de la Humanidad, se definió en 1998 por iniciativa del Consejo de Monumentos Nacionales, una lista tentativa de sitios y monumentos para nominar en la Lista de Patrimonio Mundial, consiguiendo las nominaciones para las Iglesias de Chiloé (2000), Valparaíso (2003), las salitreras de Humberstone y Santa Laura (2005), y la mina de Sewell (2006). Ello ha generado orgullo y un flujo de visitantes crecientes. En el caso de Isla de Pascua, con su atractiva historia, su espectacular paisaje, la nominación confirma lo ya conocido y le da realce internacional. Sobre todo para la ciudad de Valparaíso la nominación ha sido relevante en términos de desarrollo. Valparaíso, popularmente llamada la perla del Pacífico, con un emplazamiento geográfico de mucha belleza, fue un puerto pujante e innovador y tremendamente activo a partir de la Independencia y durante todo el siglo XIX, y sufrió luego una lenta decadencia a partir de la apertura del canal de Panamá. Por ello el turismo es una alternativa efectiva e importante de generación de recursos, y la nominación ha consolidado una oportunidad que la ciudad ha ido tomando lentamente. Sin embargo la conservación de todos estos sitios es de gran complejidad, pues implica no sólo un monumento sino en algunos casos un territorio. El país no ha destinado recursos específicos para este fin, y la responsabilidad, una vez conseguida la nominación, ha recaído principalmente en las entidades locales. Se carece aún de planes de manejo que permitan un uso sustentable, a lo que se suma la inexistencia de una normativa que haga compatible los anhelos y exigencias de conservación, con la legislación vigente, definida a través de la Ley General de Urbanismo y Construcciones, un problema de difícil solución con la rigurosa normativa antisísmica que tiene Chile. Esta conflicto es efectivo, pues gran parte de los edificios que se quieren conservar fueron construidos con anterioridad a la dictación de dicha norma, pero al restaurarse y específicamente si cambian su destino de uso (de claustro a oficina, de vivienda a universidad) deben acogerse a la normativa actual, lo que en muchas ocasiones implica cambiar el concepto estructural del edificio, con las dificultades que ello conlleva en términos estéticos, de originalidad y de costo. Quienes quieren restaurar entonces algún inmueble deben recorrer una y otra instancia reguladora, las que en muchas ocasiones les dan indicaciones todas válidas per se, pero contradictorias entre sí. Todo lo cual encarece y desanima, causando finalmente la destinación de esos recursos a otras iniciativas, como las nuevas construcciones. Considero este un aspecto esencial para el futuro de conservación en Chile, y sería deseable que el Consejo de Monumentos Nacionales en conjunto con las universidades abordasen este tipo de problemas en sus temas de tesis. 


\section{Imagen País, identidad y democracia}

Existe actualmente en Chile una conciencia creciente que el desarrollo del país está fuertemente vinculado a la fuerza de su cultura y que ésta se fundamenta en su identidad. Con el objetivo de conseguir un mejor posicionamiento de sus productos, el país está preocupado de crear y transmitir una Imagen País (ha creado recientemente una fundación con ese fin) y sabe que el concepto de "marca país" es un intangible que puede resumirse en la asociación directa entre productos, lugares y personajes (Pantuso, 2003). Hay creciente conciencia de que la carencia de una identidad definida afecta muchas actividades productivas, tales como el turismo, el diseño y la promoción de productos nacionales y que sin duda las debilidades del sistema educacional, ampliamente debatido en cada campaña electoral están de la misma manera vinculadas a la ausencia de un fuerte sustrato cultural, que permita desarrollar en la ciudadanía una visión crítica de su entorno y situación.

Progresivamente se señala que el patrimonio contribuye a crear una sociedad más democrática, pues los espacios públicos históricos, ubicados generalmente en los centros de las ciudades, están disponibles para todos por igual, generan oportunidades de intercambio y convivencia entre distintos estamentos de la sociedad, forja también sentido de pertenencia e identidad y respeto por la diversidad.

\section{Una nueva institucionalidad para el patrimonio cultural chileno}

Los antecedentes anteriormente expuestos son una selección de aspectos que buscan dar cuenta del genuino interés y del debate que se ha instalado en el país por la conservación y difusión del patrimonio cultural. En este contexto se inserta la discusión de la actual reformulación de la institucionalidad para el patrimonio cultural, lo que tiene una cierta urgencia, pues durante el gobierno de Ricardo Lagos, y con el objetivo de promover la creación artística en el país, se creó en el año 2003 el Consejo Nacional de la Cultura y las Artes [www.cnca.cl], una entidad colegiada, cuyo presidente tiene rango de Ministro de Estado. En ese momento se optó por dejar fuera de ese Consejo a la Dirección de Bibliotecas, Archivos y Museos y al Consejo de Monumentos Nacionales, creándose de esa manera una ambigüedad que genera frecuentes inconvenientes $y$ descoordinaciones, pues entre ambas reparticiones existe cierta superposición de funciones, que generan tensión y hacen ineficiente el uso de los recursos públicos. De tal manera que actualmente la institucionalidad del patrimonio, incluidos el Consejo de Monumentos Nacionales y los principales museos del país, son una dependencia del Ministerio de Educación, con una débil vinculación con el CNCA. Preocupada ante ello el actual gobierno de Michelle Bachelet, formó una Comisión para la Institucionalidad del Patrimonio (CIP) la que en su diagnóstico explicó la falta de una mirada global del Patrimonio con una política de Estado que canalice la preocupación nacional sobre la materia, y destacó entre otros aspectos que hay lenguas autóctonas que se deterioran, edificios amenazados o destruidos, sitios arqueológicos abandonados, manifestaciones populares subvaloradas, señalando que el país requiere de un esfuerzo vigoroso y ambicioso, de una política patrimonial prioritaria que esté a la altura del desafío (CIP 2007).

Recientemente y casi al término de su mandato, el ejecutivo formuló un proyecto para la creación del Instituto del Patrimonio Cultural. "Este busca un desarrollo más amplio que el permitido por la actual institucionalidad. Junto con crear un servicio público especializado, se pretende centralizar ciertos procesos decisorios, proponer políticas públicas en la materia, coordinar el trabajo de los organismos ya existentes y dotar de recursos a la acción patrimonial (Presidencia, 2009). Lo propuesto no difiere mucho de la actual institucionalidad, al igual que la existente, reúne a la actual Dirección de Bibliotecas, Archivos y Museos y al Consejo de Monumentos Nacionales, nuevamente bajo la dependencia del Ministerio de Educación. Deja fuera a otros entidades con fuerte injerencia en la conservación del patrimonio, como el Departamento de Patrimonio Arquitectónico del Ministerio de Obras Públicas y no resuelve en forma clara la doble institucionalidad cultural, pues si 
bien crea un Consejo del Patrimonio Cultural, que incluye al Ministro de Cultura, que a su vez es Presidente del Consejo de la Cultura, mantiene dos entes desvinculados entre sí.

La propuesta acierta en cuanto a que, siguiendo la tendencia internacional, incluye expresamente al patrimonio inmaterial. También propone una estructura regional antes inexistente y la indispensable creación de archivos regionales, situación pendiente desde la reforma de mediado de los 70 del siglo pasado que creó la estructura administrativa regional actual. También es interesante la creación de un Fondo del Patrimonio Cultural con el objeto de "financiar la ejecución total o parcial de proyectos, programas, actividades y medidas de identificación, registro, investigación, difusión, valoración, protección, conservación y salvaguardia del patrimonio cultural." (Presidencia, 2009:7). Los recursos de este fondo "serán asignados por concurso público y en casos calificados por asignación directa” (Presidencia, 2009:12). La creación de este fondo es valiosa: en la actualidad los recursos para el patrimonio son escasos, muchos de ellos conseguidos a través de donaciones con la intermediación de corporaciones, donde cabe destacar la notable labor que ha realizado la industria de la minería en los últimos años. El fondo abre la oportunidad a muchas entidades, sin acceso a estos entes privados, pero no contribuye a la implementación de acciones estables y permanentes, ni a fortalecer las instituciones, actualmente frágiles. Las pocas instituciones que poseen buenos equipos profesionales podrán postular y reforzar su quehacer, veo extremadamente dificultoso que una pequeña entidad de provincia, con apenas un profesional a cargo, logre asignarse un concurso. Lo más probable es que los proyectos surjan de grupos de especialistas privados, que propongan a uno u otro museo o municipio algún novedoso proyecto, el que una vez ejecutado difícilmente logre una continuidad.

La propuesta no incluye una modificación a la ley de Monumentos Nacionales, tal vez el principal escollo que el patrimonio chileno debe lograr superar. Esta Ley, del año 1970, es tremendamente regresiva, pues obliga a individuos a cargar con un costo, cuyo beneficio es colectivo. Se han sugerido algunas propuestas para otorgar beneficios tributarios, con el fin de incorporar de mejor manera al sector privado en la protección del patrimonio, pero ello no ha sido acogido hasta la fecha por el ejecutivo.

Tampoco avanza esta nueva propuesta legislativa en la urgente tarea de dotar a las instituciones nacionales de gran tradición republicana como son la Biblioteca Nacional, los Museos Nacionales y el Archivo Nacional y a aquellas que han surgido con el tiempo tales como los museos regionales y el CNCR de los recursos necesarios, para cumplir con sus funciones y para financiar los nuevos temas que son de interés hoy, como la preservación digital. En el aparato estatal relativo al patrimonio cultural, es endémico el problema de personal, pues todas estas instituciones trabajan con personal muy escaso, sub-pagado en relación a otras entidades estatales y académicas, con un alto número de personas con contratos transitorios o por proyectos específicos. La situación es compleja en Santiago y dramática en el resto de las regiones del país. En el país existen sólo cerca de diez instituciones que posean laboratorios de conservación. Los conservadores-restauradores que trabajan fuera de Santiago pueden ser contados con los dedos de una mano. En cuanto a los inmuebles que acogen a estas instituciones, si bien se están realizando esfuerzos significativos, muchos de ellos tienen serias falencias de infraestructura, lo que restringe severamente su quehacer. Algunos están al borde del colapso en cuanto a espacios disponibles, viéndose amenazando el cumplimiento de sus obligaciones legales. Ello dificulta enormemente la labor de conservación y restauración, pues no hay plazas para la contratación de personal especializado, ni la infraestructura que se requiere para un trabajo de calidad.

\section{Las asociaciones profesionales}

Es notable, por su constancia y calidad, la labor que realiza el Comité Nacional de Conservación Textil [www.cnct.cl], entidad creada en 1987, que reúne a profesionales chilenos y extranjeros 
vinculados a la conservación e investigación del patrimonio textil. El comité organiza una reunión anual, publica en boletines y actas los trabajos de sus integrantes, realiza cursos de perfeccionamiento y otorga patrocinio a sus integrantes en solicitudes a becas y auspicios. Destacable es el "Manual de Conservación Preventiva de Textiles" y el "Informe-Catastro del Patrimonio Textil Chileno", ambas publicaciones que dan cuenta de un trabajo consistente y serio.

También es interesante constatar que en noviembre de 2005 se constituyó formalmente la Asociación Gremial de Conservadores - Restauradores de Chile, [www.agcr.cl] conformada a la fecha ya por 82 miembros que trabajan en la preservación del patrimonio cultural, en las áreas de arqueología, papel, pintura, textil, monumentos y fotografía. Esta asociación, que tiene como objetivo el promover el reconocimiento de la disciplina y proteger la labor del conservadorrestaurador estimulando el desarrollo profesional de sus asociados, se ha hecho cargo del congreso chileno de conservación y restauración, el que se realiza tri-anualmente y cuya tercera versión realizada el año 2007 tuvo gran éxito de asistencia y calidad. La asociación publicó también un Código de Ética, consiguiendo en su corta vida ya algunos éxitos notables.

ICOMOS-Chile, formado en Chile el año 1969 e ICOM-Chile son entidades que no han logrado aún tener una efectiva presencia en el quehacer patrimonial en Chile, siempre con altos y bajos, dependiendo de los presidentes de turno consiguen acciones más bien aisladas. Como ejemplo de ello se puede señalar que sus presidentes no han sido mayormente considerados en la discusión de la nueva institucionalidad del patrimonio ni han sido incorporados en la propuesta para el Consejo del Patrimonio Cultural.

\section{La formación profesional de conservadores y restauradores}

El escenario antes descrito es relevante para comprender el momento actual del quehacer en el país en el ámbito del patrimonio cultural, e insertar en este ámbito el devenir de los diferentes programas de formación. Como se desprende de la descripción y análisis que hago a continuación nos encontramos ante una situación bastante compleja y hasta confusa, se ofrecen actualmente una carrera de pregrado, dos magíster, un doctorado y diversos diplomados o postítulos, según se explica en la tabla adjunta. [tabla 1]

Para nosotros en el CNCR es lamentable constatar que no haya podido perdurar en el tiempo el primer programa de Formación de Conservadores/Restauradores que se inició en el año 1984 en un la Escuela de Arte de la Pontificia Universidad Católica de Chile en convenio con el Centro Nacional de Conservación y Restauración [www.cncr.cl] de la Dirección de Bibliotecas, Archivos y Museos. Dicho convenio tuvo como propósito formar profesionales capacitados teórica y prácticamente en la conservación y restauración del patrimonio mueble (Krebs, 1997). La participación del CNCR se mantuvo hasta el año 1992 y una reestructuración general de la Escuela de Arte, sumado a la falta de recursos económicos, de infraestructura y a una insuficiente planta académica estable llevó finalmente a cerrar el programa a fines del año 2008, cuando concluyeron sus estudios los últimos alumnos. Del programa original sólo quedan tres cursos de extensión (conservación en obras de madera, conservación preventiva y patrimonio cultural) que se ofrecen aislados entre sí, y pueden ser tomados por cualquier interesado sin mediar requisitos de admisión. 
Programas de pre y post grado vinculados a la conservación y restauración del patrimonio (vigentes al 2009)

\begin{tabular}{|c|c|c|c|c|c|}
\hline Universidad & Nombre del programa & $\begin{array}{l}\text { Tipo de } \\
\text { programa }\end{array}$ & $\begin{array}{l}\text { Año de } \\
\text { creación }\end{array}$ & Duración & Restauración \\
\hline $\begin{array}{l}\text { Universidad Internacional SEK- } \\
\text { Chile, Facultad de Estudios del } \\
\text { Patrimonio Cultural }\end{array}$ & $\begin{array}{l}\text { Conservación y Restauración } \\
\text { de Bienes Culturales } \\
\text { Museables }\end{array}$ & Licenciatura & 2003 & 8 semestres & SI \\
\hline Universidad de Los Andes & $\begin{array}{l}\text { Historia y Gestión del } \\
\text { Patrimonio Cultural }\end{array}$ & Máster & 2004 & 4 semestres & $\mathrm{NO}$ \\
\hline $\begin{array}{l}\text { Universidad de Playa Ancha } \\
\text { Facultad de Arte }\end{array}$ & Arte mención Patrimonio & Magíster & & $\begin{array}{l}4 \text { semestres }+ \\
\text { tesis }\end{array}$ & SI \\
\hline $\begin{array}{l}\text { Universidad Central de Chile } \\
\text { Facultad de Arquitectura, } \\
\text { Urbanismo y Paisaje }\end{array}$ & $\begin{array}{l}\text { Arquitectura y Patrimonio } \\
\text { Cultural Ambiental }\end{array}$ & Doctorado & 2001 & 6 semestres & $\mathrm{NO}$ \\
\hline $\begin{array}{l}\text { Pontificia Universidad Católica de } \\
\text { Chile, Facultad de Arquitectura, } \\
\text { Diseño y Estudios Urbanos }\end{array}$ & $\begin{array}{l}\text { Gestión, Documentación y } \\
\text { Manejo del Patrimonio } \\
\text { Arquitectónico, Urbano y } \\
\text { Paisajes Culturales }\end{array}$ & Diplomado & 2009 & 1 semestre & $\mathrm{NO}$ \\
\hline $\begin{array}{l}\text { Universidad Ciencia e } \\
\text { Información (UCINF), Dirección } \\
\text { de Extensión }\end{array}$ & $\begin{array}{l}\text { Gestión Cultural Aplicada al } \\
\text { Patrimonio }\end{array}$ & Diplomado & 2004 & 130 horas & $\mathrm{NO}$ \\
\hline $\begin{array}{l}\text { Universidad de Humanismo } \\
\text { Cristiano }\end{array}$ & $\begin{array}{l}\text { Especialización en } \\
\text { Patrimonio Histórico - } \\
\text { Cultural }\end{array}$ & Diplomado & 2008 & 3 trimestres & $\mathrm{NO}$ \\
\hline $\begin{array}{l}\text { Universidad de Chile, Facultad de } \\
\text { Arquitectura y Urbanismo }\end{array}$ & $\begin{array}{l}\text { Conservación y Restauración } \\
\text { Arquitectónica }\end{array}$ & Postítulo & 2006 & $\begin{array}{l}2 \text { semestres }+ \\
\text { tesis }\end{array}$ & SI \\
\hline $\begin{array}{l}\text { Universidad de Chile, Facultad de } \\
\text { Artes }\end{array}$ & $\begin{array}{l}\text { Restauración del Patrimonio } \\
\text { Cultural Mueble }\end{array}$ & Postítulo & 1998 & & SI \\
\hline
\end{tabular}

Señalo que es lamentable, pues gran parte del desarrollo de la disciplina de la conservación/restauración del patrimonio mueble ha sido posible debido a los ex - alumnos de ese plantel, gracias a los cuales se ha podido establecer en Chile estándares de trabajo muy consistentes en el ámbito del patrimonio mueble. Dicho programa fue pionero y se ajustaba al nivel de desarrollo del país y a las necesidades de patrimonio chileno. Si bien otorgaba una formación de pre-grado y no lograba alumnos con un alto grado de especialización en alguna de las especialidades de la conservación, sí entregaba conceptos teóricos contundentes, inculcaba un criterio general y conocimientos tales que después a través de la práctica o de pasantías en centros de conservación, museos o bibliotecas tenían los elementos suficientes para desarrollar una especialización, según sus intereses u oportunidades. 
El programa se construía sobre un ciclo básico de formación general en arte de cuatro semestres de duración, al que sumaban cinco de especialización en conservación, cuyo programa se construía sobre tres líneas temáticas: teoría, ciencias y taller, a los que los alumnos debían sumar cursos de profundización en función de sus intereses, los que se orientaban a reforzar la formación teórica o las prácticas de taller. Finalmente el alumno debía realizar una memoria profesional y rendir un examen de titulación (Seguel, 2002). Si bien carezco de cifras oficiales estimo que deben haber egresado de dicho programa alrededor de 80 profesionales.

Dicho espacio ha sido tomado, a partir del año 2003, por la universidad SEK, una universidad privada, que ofrece un programa de formación en Conservación y Restauración de Bienes Culturales, también en un nivel de pre-grado que otorga un grado de licenciado y el título profesional de conservador/restaurador. Si bien el CNCR no tiene una participación formal en este programa, muchos de sus profesionales dictan cursos en él y los alumnos con frecuencia visitan el Centro. Este programa se construye sobre la base de una licenciatura y busca dar un "enfoque museológico de la disciplina de la restauración, poniendo énfasis en la función social del patrimonio cultural y su relación con el público, e incorpora además la gestión y el diseño de exhibiciones". Con la intención de dar mayores alternativas laborales, la convocatoria señala a los interesados que "podrán desempeñarse en el diseño y gestión de proyectos de conservación y exhibición, vinculados a planes de desarrollo en comunidades locales e instituciones del patrimonio, así como en el diseño de exhibiciones en museos, bibliotecas y galerías. Además podrán ejercer en laboratorios de conservación y restauración, como encargado de colecciones privadas o impartir docencia en universidades o capacitación para personal dedicado al patrimonio cultural" 2 . En los últimos años, estos alumnos han comenzado ya a integrarse al mercado laboral.

Dos planteles superiores brindan programas de Magíster o Master. La Universidad de los Andes, ofrece un Master de cuatro semestres de duración, dirigido a una enorme variedad de profesionales, tales como historiadores, antropólogos, arqueólogos, pedagogos, arquitectos, diseñadores, sociólogos, periodistas, abogados y, en general, a todos aquellos profesionales del área de las humanidades interesados en rescatar y revalorizar el patrimonio. Busca combinar tres líneas de trabajo: historia, patrimonio y gestión y se propone formar especialistas capaces de generar y ejecutar proyectos patrimoniales con un enfoque integral...y formular proyectos que abarquen una vasta gama de problemas, desde lo cultural a lo social; ejecutados mediante un método interdisciplinario, que logren involucrar al Estado y al sector privado, y que, por último, tengan un efecto multiplicador en los diferentes ámbitos de la comunidad, a través de la educación y las comunicaciones". El módulo de gestión para la conservación del patrimonio cultural es dictado en las dependencias del CNCR, en ocho clases dadas por seis profesionales del staff del Centro.

Fuera de la capital del país, el único programa en este ámbito es ofrecido por la Universidad de Playa Ancha en Valparaíso un Magíster de Arte con Mención en Patrimonio, también de cuatro semestres de duración. "Este programa tiene como objetivo la formación de investigadores al más alto nivel científico que sean capaces de producir, integrar, aplicar y diseminar conocimientos sobre el conjunto de las manifestaciones pertenecientes al Patrimonio Tangible e Intangible del medio local, regional y nacional como bases para un mejoramiento sostenible en el contexto de su uso social."

El único programa de doctorado es ofrecido por el Centro de Estudios del Patrimonio de la Universidad Central en conjunto con el Departamento de Historia, Teoría y Composición Arquitectónica de la Universidad de Sevilla. Inicia, ahora en junio del año 2009, su tercera versión del Doctorado de Arquitectura y Patrimonio Cultural-Ambiental, pero lamentablemente explica en su página de convocatoria que será "la última vez que éste se imparta en su formato actual, ya que de acuerdo a los dictámenes del Parlamento de la Unión Europea de Naciones, los estados parte sólo podrán dictar sus programas de post grado en territorio europeo"’. Ello significará que 
nuevamente se interrumpirá una iniciativa, y no logrará crear una escuela de alumnos con un planteamiento común.

Para esta última versión invita a participar de él "a arqueólogos, arquitectos, antropólogos, ecólogos paisajistas, geógrafos, licenciados en arte e historia y otros profesionales universitarios interesados en el tema del patrimonio arquitectónico, urbanístico y del paisaje. El doctorado partió el 2001 y tiene una duración de tres años, donde el primero está compuesto por 200 horas presenciales, mientras que el segundo y el tercero corresponden al período de investigación y tesis. La defensa de esta última se efectúa en Sevilla, ante el Tribunal Único de la universidad española". El programa aborda el patrimonio desde una perspectiva de la gestión y planificación y desarrolla para ello las siguientes tres líneas de trabajo:

Línea 1: Arquitectura como patrimonio (claves historiográficas e interpretativas, patrimonio industrial como arqueología de la era mecánica, patrimonio contemporáneo en Latinoamérica)

Línea 2: Espacio público como patrimonio (valoración patrimonial de espacios públicos, espacios públicos urbanos)

Línea 3: Paisaje y territorio como patrimonio (paisaje y espacios naturales: claves para su gestión sostenible, el paisaje en la construcción cultural del territorio, paisajes culturales: reconocimiento, conceptos clave y ordenación) 4 .

Diversas universidades ofrecen Diplomados o Postítulos, programas con duración y niveles de exigencia disímiles. No pretenden otorgar grado académico sino dar la oportunidad de adquisición o profundización de conocimientos, en base a cursos o a clases magistrales ofrecidas por una selección de expositores.

La Pontificia Universidad Católica ofrece en esta modalidad, a partir del año en curso, en un semestre de duración y cien horas cronológicas, el Diplomado en Gestión, Documentación y Manejo del Patrimonio Arquitectónico y Urbano: Nuevas visiones para los desafíos contemporáneos. Su objetivo principal es "capacitar al alumno en el desarrollo de criterios de identificación, protección y gestión de los diferentes inmuebles o áreas urbanas con valores patrimoniales, así como las estrategias para generar programas o acciones a través de la incorporación no solo de los valores patrimoniales arquitectónicos y/o urbanos, sino además de las variables sociales y económicas cada día más presentes para preservar, conservar, rehabilitar y revitalizar dicho patrimonio"s.

La Universidad de Chile ofrece dos instancias que denomina cursos de especialización de postítulo uno desde la Facultad de Arquitectura [www.fau.cl] y otro desde la de Arte. El Curso de Especialización de Postítulo en Conservación y Restauración Arquitectónica está dirigido a arquitectos, ingenieros, constructores civiles. Con dos semestres de duración, divididos en las áreas de historia, restauración, tecnología, metodología y un seminario final, tiene como objetivo "crear una instancia de especialización tendiente al desarrollo de la Conservación y Restauración Arquitectónica como conocimiento multidisciplinar". El Curso de Especialización en Postítulo en Restauración del Patrimonio Cultural Muebles ${ }^{6}$ propone una ambiciosa malla académica, que contempla cursos de restauración de cerámica, audiovisual, metales, objetos arqueológicos, madera y cuero, junto a química, física, biología, análisis científico y derecho aplicado. El postítulo de dos años de duración, entrega estos múltiples módulos enfocados a las distintas áreas de intervención, pero se echa de menos una visión global teórica, un concepto vinculado a las colecciones y a la gestión de riesgos, la entrega de cursos prácticos, como también algún grado de especialización. Como no pone requisitos de admisión, no consigue situar a sus alumnos en algún escalafón académico comparable. 


\section{La formación desde el Centro Nacional de Conservación y Restauración}

La formación de especialistas ha sido para el Centro Nacional de Conservación y Restauración un aspecto prioritario desde sus inicios en el año 1982, cuando se crea éste como consecuencia del diagnóstico de los museos chilenos que realiza la Dirección de Bibliotecas, Archivos y Museos con apoyo del Programa de las Naciones Unidas para el Desarrollo, PNUD (Dibam, 1984). Desde esa fecha el CNCR ha entendido como parte de su mandato el promover la formación, con el propósito fomentar la profesionalización de la disciplina en el país, llegando a definir cuatro líneas de acción:

1. Apoyo a la formación universitaria, según lo descrito más arriba.

2. Cursos de especialización para conservadores restauradores, para los cuales no hay un programa establecido, sino que se dictan según estrategias definidas para introducir nuevos temas.

3. Cursos orientados a transmitir conceptos de conservación preventiva para el personal de instituciones que cautelan patrimonio cultural. Para ello se dictan cursos en las instalaciones de nuestro Centro, pero también se generan iniciativas para insertar el tema de la conservación preventiva en el país, desarrollando un programa de cursos en diversas regiones del país en la década del 80 para los museos (Krebs, 1997) y otro también con un énfasis regional en la década de los 90 para las bibliotecas y archivos (Mujica, 2007).

4. Programa de prácticas y pasantías, para el cual se realizó un seminario internacional en el año 2000, que nos permitió comprender los aspectos esenciales que debía cumplir un programa de esta naturaleza. Este es tal vez el único programa formal de este tipo en el país, ha tenido gran acogida (Krebs y Sáez, 2007) y a pesar de no contar con becas asociadas ha significado una opción para muchos profesionales, especialmente aquellos que recién se han titulado para adquirir conocimientos prácticos y específicos en alguna de las áreas que se ofrecen.

\section{Conclusiones:}

Las particularidades del mercado laboral del ámbito del patrimonio cultural chileno sumado a las características de la estructura universitaria del país, que obligan a que tengan que auto sustentarse, dificulta ofrecer carreras de formación tendientes a la especialización en algún campo específico de la conservación. Por ello los centros de formación, ofrecen un producto educativo no excesivamente especializado ni enfocado a un grupo definido para intentar llenar año a año las plazas. El alto costo de las carreras hace por otro lado que no sea posible ofrecer carreras de más larga duración, lo que también lleva a dificultar una formación profunda y específica. Las pocas plazas estables existentes en las instituciones llevan a que se requiera de profesionales capaces de trabajar sobre la base de proyectos, con creatividad y capacidad para una continua búsqueda de recursos, ya sea a través de la participación de concursos para los fondos concursables estatales, o bien para conquistar empresas interesadas en donar fondos para ciertos proyectos. La suma de todos esos factores hace que actualmente haya tomado tanta relevancia la formación en gestión, más que en el estudio de la patología de los materiales o bien metodologías y técnicas de intervención. Aún no podemos tener certeza de cuáles de los programas universitarios lograrán perdurar en el tiempo, es probable que las últimas tendencias descritas en cuanto a la instalación del patrimonio cultural en la agenda pública lleven a consolidar algunas carreras en el futuro cercano. 


\section{Notas}

[1] "BID aprobó préstamo para conservación de patrimonio en Chile" http://www.subdere.gov.cl/1510/article-73009.html\#h2 1 [consulta 2009-06-18]

[2] SEK. "Carreras" www.uisek.cl/carreras/conservacionyrestauracion.html [consulta: 2009-0626]

[3] "Doctorado. Arquitectura y Patrimonio Cultural-Ambiental" http://arquitectura.ucentral.cl/doctorado [consulta: 2009-05-15]

[4] Ibid.

[5] "Diplomado / Gestión, Documentación y Manejo del Patrimonio Arquitectónico, Urbano y Paisajes Culturales" http:// fadeu.puc.cl/direccion-de-educacion-continua-ycomunicaciones/diplomado-patrimonio-y ciudad/ [consulta 2009-06-26]

[6] "Restauración del patrimonio cultural mueble" http://www.postgradoartes.uchile.cl/postitulo_especializacion/post restpatrimcultural.php [consulta: 2009-07-11]

\section{Bibliografía}

COMISIÓN DE INSTITUCIONALIDAD PATRIMONIAL (2007). Propuestas de perfeccionamiento de políticas, instrumentos e institucionalidad patrimonial. Abril, 2007: 9.

DIBAM (1984). Los museos de Chile (diagnóstico). Santiago de Chile: Dirección de Bibliotecas, Archivos y Museos, Colección Chile y su cultura.

KREBS, M. (1997). “Formación y capacitación en el CNCR”, Revista Conserva, 1: 7-12.

KREBS, M. y SÁEZ, A. (2007). "Las prácticas y pasantías: una estrategia de aprendizaje y actualización", Revista Conserva, 11: 149-158.

BACHELET, M. (2009). Mensaje de S.E. Michelle Bachelet, 18 de mayo de 2009. Santiago: Presidencia de la República.

MUJICA, P. (2007). "Capacitación en conservación para las Bibliotecas y Archivos de Chile: Programas para lograr un alcance nacional”. Revista Conserva, 11: 137 - 148.

PANTUSO, C. (2003). "El patrimonio cultural y natural, un capital irremplazable", Revista Peronistas, 3. www.cepag.com.ar/pdf/peronistas_3/pantuso.pdf [consulta: 2008-10-30]

RODRIGUEZ, H. (2008). "Incertidumbre patrimonial", www.nuestro.cl/comunidad/aportes/carta_hernan_rodriguez1.htm [consulta: 2008-08-30]

SEGUEL, R.. (2003). La formación de conservadores y restauradores en Chile, avances y desafíos. Conservación, gestión y valorización de los bienes culturales en Uruguay, en el Mercosury en Chile, Roma: Instituto Italo-latino americano.

SERRANO, V. (2007). "El patrimonio no es intocable: debe convivir con la comunidad" Categorías: Tema Central, Entrevistas, 130 / Patrimonio. www.revistaca.cl/2007/07/veronica-serrano- $\%$ E2\%80\%9Celpatrimonio-no-es-intocable-debe-convivir-con-la-comunidad $\% \mathrm{E} 2 \% 80 \% 9 \mathrm{D} /$ [consulta: 2009-06-25] 


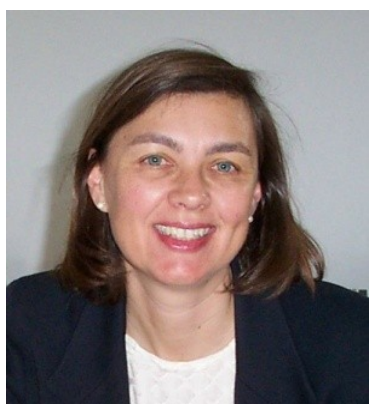

\section{Krebs Kaulen}

Centro Nacional de Conservación y Restauración

Claustro de la Recoleta Dominica

Tabaré 654 - Recoleta - Santiago de Chile.

Tel: (56-2) 7382010 - Fax: (56-2) 7320252

mkrebs@cncr.cl

Magdalena Krebs Kaulen es Directora Centro Nacional de Conservación y Restauración de la Dibam. Es arquitecta de la Pontificia Universidad Católica de Chile. Ingresó a la Dirección de Bibliotecas, Archivos y Museos (DIBAM) en 1983 para desempeñarse en el Departamento de Documentación del Patrimonio Cultural, y en 1988 asumió la dirección del CNCR. Entre los años 1995 y 2003 y nuevamente a partir del año 2005 es miembro del Consejo del International Centre for the Study of the Preservation and Restoration of Cultural Property (ICCROM) con sede en Roma. Es directora de la revista "Conserva" del CNCR y miembro del Comité Directivo de la DIBAM.

Su labor en el CNCR ha consistido en dirigir la organización, velando por su desarrollo y contribuyendo desde allí a la divulgación de la importancia del patrimonio cultural en Chile. Ha impulsado la profesionalización de la conservación, gestionando para ello cursos y proyectos de conservación en colaboración con museos, bibliotecas y archivos de todo el país y estableciendo vínculos con instituciones extranjeras e internacionales. También ha colaborado en la formulación de programas de conservación para la Pontificia Universidad Católica de Chile. Es asesora y profesora del programa de Master en Gestión Cultural de la Facultad de Historia de la Universidad de Los Andes de Santiago de Chile. Desde el año 2000 al 2003 estuvo encargada de realizar la gestión del proyecto del Claustro Recoleta Dominica, coordinando tanto el programa general del proyecto como los trabajos de restauración. Ha contribuido a instaurar los Congresos Chilenos de Conservación y Restauración, que se desarrollan trienalmente desde el año 2001. Desde el año 2008 es Coordinadora del “Grupo de Publicaciones y Difusión” del Programa ICCROM-LATAM. 